\title{
Ampullary metastasis from breast cancer: an unusual finding
}

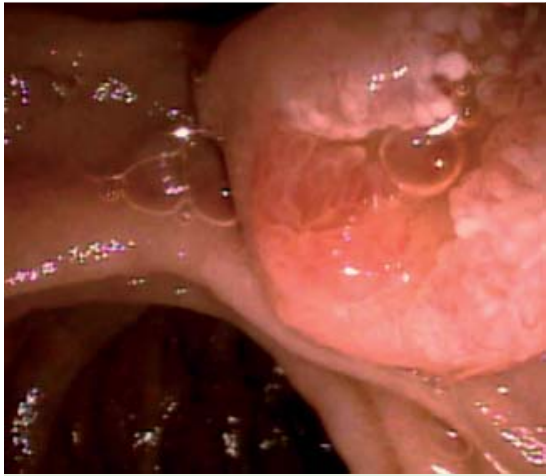

Fig. 1 Prominent "adenomatous-appearing" ampulla.

A third of women with breast cancer will develop metastatic disease [1]. However, gastrointestinal involvement with metastatic breast cancer is rare and may pose a diagnostic challenge [2-4]. We present two cases of metastatic breast cancer with unusual gastrointestinal findings.

Case 1: A 39-year-old woman with metastatic breast cancer presented with nausea and vomiting. Laboratory results revealed: total bilirubin $101 \mu \mathrm{mol} / \mathrm{L}$, direct bilirubin $63.2 \mu \mathrm{mol} / \mathrm{L}$, aspartate aminotransferase (AST) $111 \mathrm{IU} / \mathrm{L}$, alanine aminotransferase (ALT) $216 \mathrm{IU} / \mathrm{L}$, and alkaline phosphatase $122 \mathrm{IU} / \mathrm{L}$. An abdominal ultrasound showed dilated bile ducts as well as a dilated common bile duct (CBD) of $14 \mathrm{~mm}$. Endoscopic retrograde cholangiopancreatography (ERCP) revealed an "adenomatous"-appearing ampulla (๑ Fig. 1).

The cholangiogram revealed a stricture in the distal CBD with proximal dilatation. Histologic sections show an infiltrate of individual round, discohesive, malignant cells within the lamina propria, characteristic of metastatic lobular carcinoma of the breast. Immunohistochemical stains for broad-spectrum cytokeratin (AE1/3) were strongly reactive in the malignant cells and differentiating the cells from histiocytes ( $\bullet$ Fig. 2 ), confirming the diagnosis of metastatic carcinoma from breast primary.

Unfortunately, the patient underwent a complicated course, culminating in gastric outlet obstruction requiring gastroenterostomy.

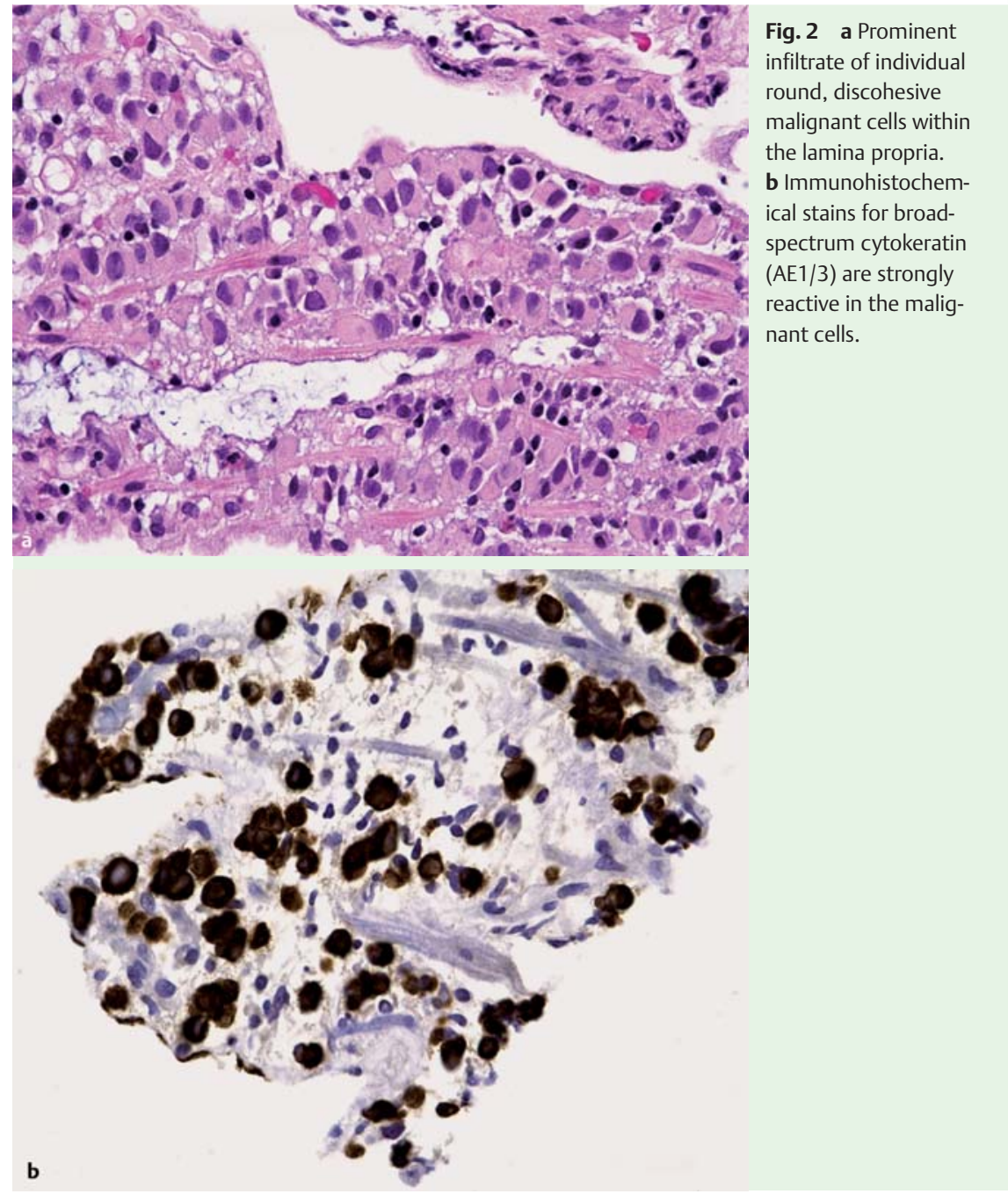

Case 2: A 66-year-old white woman with stage II invasive ductal adenocarcinoma involving the left breast presented with fatigue, 2 years after the initial diagnosis. A computed tomography (CT) scan of the abdomen at the time revealed a CBD of $1.3 \mathrm{~cm}$. Liver function tests revealed: total bilirubin $10.26 \mu \mathrm{mol} / \mathrm{L}$, AST $43 \mathrm{IU} / \mathrm{L}$, and ALT $39 \mathrm{IU} / \mathrm{L}, \gamma$-glutamyl transferase 254 IU/L, and alkaline phosphatase $279 \mathrm{IU} / \mathrm{L}$. ERCP showed an abnormal ampulla with a distal CBD stricture.

At higher power, the glands were irregular with malignant cytologic features, consistent with metastatic carcinoma (๑ Fig. 3).
The patient was started on palliative chemotherapy.

A review of the literature revealed one case report of breast cancer metastasis to the ampulla [5]. Both our patients initially had mild prominence of the intrahepatic biliary tree. This was later followed by worsening of liver function and interval progression in the size of the CBD. This emphasizes the need to entertain the possibility of gastrointestinal metastasis from breast cancer at an earlier stage, especially in the presence of other findings suggestive of possible disease recurrence.

Endoscopy_UCTN_Code_CCL_1AB_2AZ_3AB 


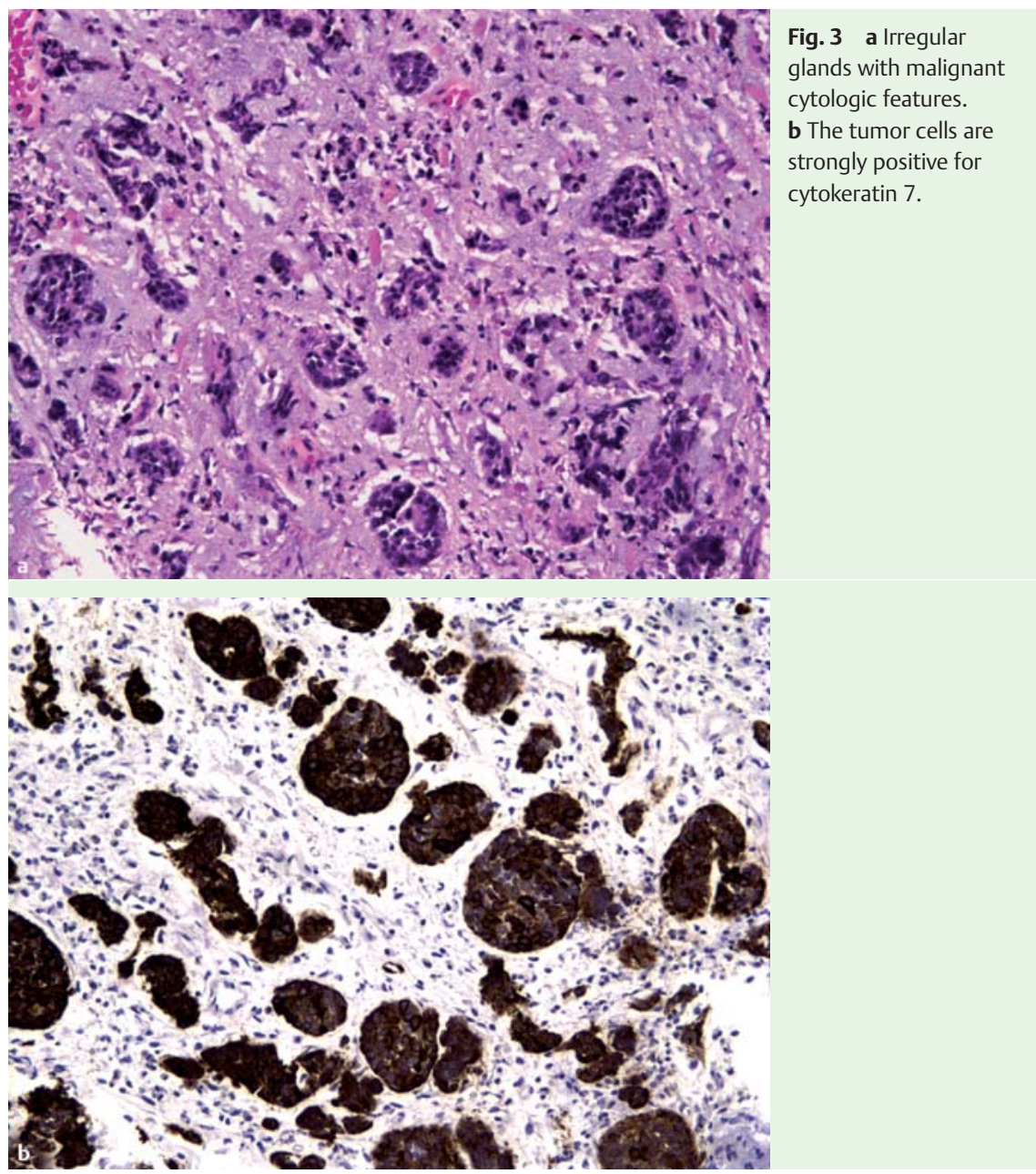

R. F. Rego, M. Atiq, N. Velchala, D. Nevin, D. P. McElreath, W. D. McKnight, F. Aduli Division of Gastroenterology, University of Arkansas for Medical Sciences, Little Rock, Arkansas, USA

\section{References}

1 Wong $K$, Henderson IC. Management of metastatic breast cancer. World J Surg 1994; 18: $98-111$

2 Lee YN. Breast carcinoma: pattern of metastasis at autopsy. J Surg Oncol 1983; 23: 175180

3 Nihon-Yanagi $Y$, Park $Y$, Ooshiro $M$ et al. A case of recurrent invasive lobular carcinoma of the breast found as metastasis to duodenum. Breast Cancer 2009; 16: 83-87

4 Mehta SA, Jagannath P, Krishnamurthy SC et al. Isolated pancreatic metastasis from locally controlled breast cancer: A case report. Int J Med 1991; 28: 48 - 50

5 Titus AS, Baron AS, Todd H. Solitary breast metastasis to the ampulla and distal common. Am Surg 1997; 63: 512 - 515

Bibliography

DOI $10.1055 / \mathrm{s}-0029-1215071$

Endoscopy 2009; 41: E278 -E279

(c) Georg Thieme Verlag KG Stuttgart · New York . ISSN 0013-726X

\section{Corresponding author}

\section{Atiq, MD}

Division of Gastroenterology,

University of Arkansas for Medical Sciences

4301 W Markham Street

ML\#567

Little Rock

Arkansas 72205

USA

Fax: +1-501-6261468

matiq@uams.edu 